\title{
Reaproveitamento de resíduo de rocha ornamental proveniente do Noroeste Fluminense em cerâmica vermelha
}

\author{
(Utilization of ornamental rock waste from \\ Northwest Fluminense in red ceramic)
}

\author{
J. M. S. Moreira, J. P. V. T. Manhães, J. N. F. Holanda \\ Grupo de Materiais Cerâmicos, LAMAV \\ Universidade Estadual do Norte Fluminense \\ Av. Alberto Lamego 2000, Campos dos Goytacazes, RJ 28013-602 \\ holanda@uenf.br
}

\begin{abstract}
Resumo
A indústria de rochas ornamentais da região Noroeste Fluminense gera grandes quantidades de resíduo fino resultante do processo de extração e corte de rochas. Este resíduo quando descartado provoca impacto ambiental negativo no meio ambiente. No presente trabalho foi feito um estudo objetivando reaproveitar tal resíduo como matéria-prima para cerâmica vermelha. Foi preparada uma série de misturas argila/resíduo contendo até $20 \%$ em peso de resíduo de rocha ornamental, e sinterizadas entre $850{ }^{\circ} \mathrm{C}$ e $1150{ }^{\circ} \mathrm{C}$. Os resultados experimentais mostraram que adições de até $20 \%$ em peso do resíduo de rocha ornamental, não promovem variações significativas na generalidade das propriedades físico-mecânicas da massa argilosa padrão. Análise por difração de raios X demonstrou que uma série de transformações de fases ocorrem durante o processo de queima.

Palavras-chave: resíduo de rocha ornamental, cerâmica vermelha, reciclagem.
\end{abstract}

\begin{abstract}
The industry of ornamental rocks from Northwest Fluminense region generates huge amounts of fine waste resulting from the extraction of rocks. This residue, as disposed, generates negative environmental impacts. In the present work a study was done aiming at using the ornamental rock powder waste as raw material for red ceramics. A series of clay/waste mixtures were prepared with contents up to $20 \mathrm{wt} . \%$ of waste, and sintered between $850{ }^{\circ} \mathrm{C}$ and $1150{ }^{\circ} \mathrm{C}$. The experimental results showed that the addition of up to $20 \mathrm{wt} \%$ of ornamental rock powder waste did not promote significant variations in the physical-mechanical properties of the pure clayey formulation used as reference. In addition, X-ray diffraction analyses demonstrated that a series of phase transformations occurred during the sintering process.
\end{abstract}

Keywords: ornamental rock waste, red ceramic, recycling.

\section{INTRODUÇÃO}

Para suprir as necessidades do mundo moderno, é necessário um aumento da produção que paulatinamente contribui para o aumento de resíduos, que nem sempre têm um destino ecologicamente correto. Como não é possível parar a produção, uma das grandes preocupações da atualidade, consiste em reaproveitar os resíduos gerados nos diversos processos produtivos.

O Brasil é um dos maiores produtores e exportadores de rochas ornamentais do mundo. Dentre elas, destaca-se o mármore, o granito propriamente dito, o diorito, e o gnaisse, comercialmente conhecidos por mármore e granito. O estado do Espírito Santo é o principal pólo de rochas ornamentais do país instalado na região de Cachoeiro de Itapemirim [1]. No estado do Rio de Janeiro, a região Noroeste também é rica em rochas ornamentais, com enfoque para o município de Santo Antônio de Pádua. As rochas ornamentais deste município são principalmente rochas graníticas [2]. No entanto, existem também em Santo Antônio de Pádua cerca de 72 empresas explorando pedras de revestimento denominadas de pedra Paduana, pedra Miracema, pedra olho de Pombo e a Pinta Rosa. Estas pedras correspondem ao produto da milonitização de um ortognaisse intrusivo.

Para o uso das rochas ornamentais na construção civil, é necessário o seu desdobramento de blocos para chapas. Este processo é responsável pelo resíduo na forma de lama. Esta lama é geralmente depositada num pátio, porém a quantidade produzida é significativa. Durante a extração e corte de pedras ornamentais no município de Santo Antônio de Pádua-RJ, são geradas enormes quantidades de resíduo na forma de lama abrasiva [3]. Um dos problemas 
enfrentado pela indústria de extração e beneficiamento de rochas ornamentais no Brasil é a poluição do meio ambiente, causado pela disposição final deste resíduo. Este resíduo pode alcançar rios, lagos, córregos e até mesmo os reservatórios naturais de água, pois eles são lançados no ecossistema sem nenhum tratamento prévio [4]. Além disso, a polpa afeta a paisagem esteticamente, necessita-se de grande espaço para a sua estocagem, e o alto custo do recolhimento e armazenamento. Ressalta-se, ainda, que este resíduo (lama) quando seco constitui-se num pó fino que provoca danos a saúde humana.

A problemática ambiental tem despertado nos últimos anos grande interesse no Brasil. As leis de controle ambiental tornaram-se mais severas e os órgãos de fiscalização ambiental tornaram-se mais eficientes. Por outro lado, os custos de disposição de resíduos de forma ecologicamente correta são elevados. Isto tem motivado a busca de alternativas tecnológicas viáveis para a disposição de resíduos industriais.

Trabalhos reportados na literatura [5-8] têm demonstrado o potencial da utilização de resíduos de rochas ornamentais, particularmente de mármore e granito, no desenvolvimento de produtos cerâmicos para construção civil. Os termos mármore e granito são muito genéricos, e sendo assim, os resíduos variam de empresa para empresa. Estes resíduos são atrativos para o aproveitamento cerâmico por serem constituídos de $\mathrm{SiO}_{2}, \mathrm{Al}_{2} \mathrm{O}_{3}, \mathrm{~K}_{2} \mathrm{O}, \mathrm{Na}_{2} \mathrm{O}$ e $\mathrm{CaO}$. Estes compostos são normalmente encontrados nas matériasprimas usadas na fabricação de produtos cerâmicos. Ressaltase também que a reutilização destes resíduos contribui para a diminuição do consumo de matérias-primas naturais, resultando em ganhos ambiental e econômico.

Oobjetivoprincipaldestetrabalhoéestudarapossibilidade de utilização de um resíduo de rocha ornamental proveniente do Noroeste Fluminense em cerâmica vermelha. O resíduo utilizado não se enquadra na classificação de resíduo de mármore e granito, mas como material sucedâneo por se tratar de um gnaisse, que é uma rocha metamórfica com menor valor agregado.

\section{MATERIAIS E MÉTODOS}

Neste trabalho foram preparadas cinco massas cerâmicas contendo adições de até $20 \%$ em peso de resíduo de rocha ornamental do tipo gnaisse (Tabela I). Na preparação destas massas, foi utilizada uma massa argilosa industrial plástica da região de Campos dos Goytacazes-RJ, que corresponde à massa padrão. O resíduo de rocha ornamental foi coletado numa empresa localizada na região de Santo Antônio de Pádua-RJ. As matérias-primas foram misturadas e homogeneizadas num misturador cilíndrico durante 15 min, e classificadas por peneiramento para $<40$ mesh. A seguir, as massas foram umidificadas para 7\% em peso de água.

A composição química das matérias-primas foi determinada por fluorescência de raios X. A análise
Tabela I - Composição das massas cerâmicas (\% em peso). [Table I - Composition of ceramic pastes (wt.\%)].

\begin{tabular}{ccc}
\hline Amostras & Massa Padrão & Resíduo \\
\hline F1 & 100 & 0 \\
F2 & 95 & 5 \\
F3 & 90 & 10 \\
F4 & 85 & 15 \\
F5 & 80 & 20 \\
\hline
\end{tabular}

mineralógica das matérias-primas foi feita por difração de raios X em um difratômetro marca SEIFERT, modelo URD 65 , utilizando-se radiação de $\mathrm{Cu}-\mathrm{K}_{\alpha}$, na faixa angular $(2 \theta)$ variando de $5^{\circ}$ a $70^{\circ}$. A granulometria das matérias-primas foi determinada por meio de uma combinação das técnicas de peneiramento e sedimentação de acordo com a norma NBR 7181 - 84 [9]. A plasticidade foi determinada de acordo com as normas NBR 6459 - 84 [10] e NBR 7180 - 84 [11].

As massas cerâmicas preparadas foram submetidas à compactação por prensagem uniaxial com açãoúnica do pistão superior, utilizando uma matriz de aço de seção retangular $(11,50$ x 2,54 x 1,0 cm³). A pressão de compactação foi de aproximadamente $26 \mathrm{MPa}$. Após a compactação, os corpos cerâmicos de seção retangular foram submetidos à secagem em estufa a $110{ }^{\circ} \mathrm{C}$ por um período de $24 \mathrm{~h}$. As seguintes propriedades tecnológicas de secagem foram determinadas: massa específica aparente e tensão de ruptura à flexão.

O processo de queima dos corpos cerâmicos foi realizado num forno elétrico tipo mufla (BRASIMET, modelo K 150 $1300{ }^{\circ} \mathrm{C}$ ). As temperaturas de patamar utilizadas foram entre 850 e $1150{ }^{\circ} \mathrm{C}$. Foi utilizado um ciclo de queima lento (24 h frio a frio). Após a queima, foram determinadas as seguintes propriedades tecnológicas: retração linear, absorção de água, massa específica aparente e tensão de ruptura à flexão (carregamento de três pontos). A identificação das fases cristalinas nos corpos cerâmicos após queima foi feita por difração de raios $\mathrm{X}$.

\section{RESULTADOS E DISCUSSÃO}

A Fig. 1 apresenta o difratograma de raios $\mathrm{X}$ das massas cerâmicas preparadas. Nesta figura também é mostrado o difratograma do resíduo de rocha ornamental. A massa cerâmica padrão (amostra F1) e o resíduo de rocha ornamental são bem distintos do ponto de vista mineralógico. O resíduo é rico em quartzo $\left(\mathrm{SiO}_{2}\right)$, feldspato potássico $\left(\mathrm{KAlSi}_{3} \mathrm{O}_{8}\right.$, microclina) e feldspato sódico ( $\mathrm{NaAlSi}_{3} \mathrm{O}_{8}$, albita). Além desses minerais, há indícios da presença de hematita e calcita. Enquanto que a massa cerâmica padrão é constituída essencialmente por caulinita $\left(2 . \mathrm{SiO}_{2} \cdot \mathrm{Al}_{2} \mathrm{O}_{3} \cdot 2 \mathrm{H}_{2} \mathrm{O}\right)$, gibsita $\left(\mathrm{Al}_{2} \mathrm{O}_{3} \cdot 3 \mathrm{H}_{2} \mathrm{O}\right)$ e quartzo. Além disso, foi detectada a presença de goetita e ilita/mica. Embora não seja possível observar com clareza na Fig. 1, a massa cerâmica padrão tende a ser enriquecida de compostos fundentes com a adição de resíduo de rocha ornamental. 


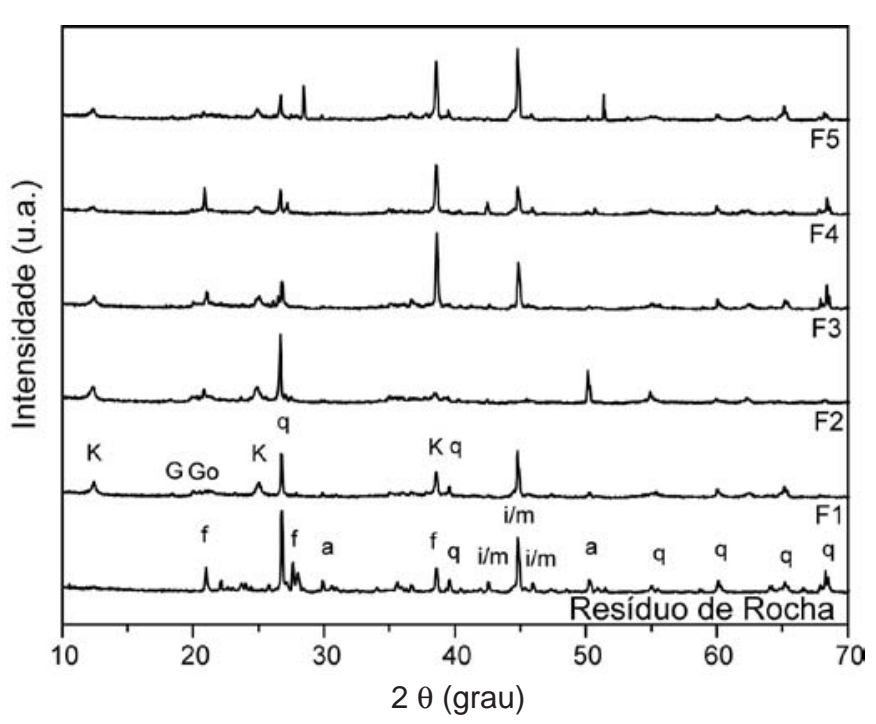

Figura 1: Difratograma de raios $\mathrm{X}$ das massas cerâmicas: K - caulinita, G - gibsita, $\mathrm{G}_{\mathrm{o}}$ - goetita, q - quartzo, i/m - ilita/mica, a - albita, $\mathrm{f}$ - feldspato potássico.

[Figure 1: X-ray diffractograms of ceramic pastes: $K$ - kaolinite, $G$ - gibbsite, $G_{o}$ goethite, q - quartz, i/m - illite/mica, a - albite, and $f$ - potash feldspar.]

As composições químicas do resíduo e da massa argilosa padrão são dadas na Tabela II. Verifica-se que o resíduo é constituído basicamente por $\mathrm{SiO}_{2}, \mathrm{Al}_{2} \mathrm{O}_{3}$ e óxidos fundentes. Isto é típico de rochas metamórficas ornamentais do tipo gnaisse. $\mathrm{O}$ conteúdo de óxidos alcalinos $\left(\mathrm{K}_{2} \mathrm{O}\right.$ e $\left.\mathrm{Na}_{2} \mathrm{O}\right)$ é relativamente alto da ordem de 6,21\%. Estes óxidos são muito importantes nas formulações cerâmicas, pois atuam como agentes fundentes ajudando a sinterização das peças cerâmicas. Os óxidos alcalinos são provenientes principalmente dos feldspatos e mica presentes no resíduo.

Tabela II - Composição química (\% em peso) das matériasprimas utilizadas.

[Table II - Chemical composition (wt.\%) of the raw materials used].

\begin{tabular}{ccc}
\hline Compostos & Massa Padrão & Resíduo \\
\hline $\mathrm{SiO}_{2}$ & 46,42 & 72,17 \\
$\mathrm{Al}_{2} \mathrm{O}_{3}$ & 27,90 & 10,80 \\
$\mathrm{Fe}_{2} \mathrm{O}_{3}$ & 9,10 & 5,04 \\
$\mathrm{CaO}$ & 0,22 & 2,33 \\
$\mathrm{MgO}$ & 0,71 & 0,94 \\
$\mathrm{~K} O$ & 1,67 & 3,87 \\
$\mathrm{Na}_{2} \mathrm{O}$ & 0,36 & 2,34 \\
$\mathrm{TiO}_{2}$ & 1,32 & 1,07 \\
$\mathrm{MnO}$ & 0,11 & 0,08 \\
$\mathrm{P}_{2} \mathrm{O}_{5}$ & 0,21 & 0,27 \\
$\mathrm{PF}$ & 11,96 & 1,08 \\
\hline
\end{tabular}

$\mathrm{PF}$ = perda ao fogo
Tabela III - Distribuição de tamanho de partículas das massas preparadas (\%).

[Table III - Particle size distribution of ceramic pastes (\%)].

\begin{tabular}{cccc}
\hline Amostras & $\begin{array}{c}\text { Fração } \\
\text { Argila } \\
(<2 \mu \mathrm{m})\end{array}$ & $\begin{array}{c}\text { Silte } \\
(2 \leq \mathrm{x}<60 \mu \mathrm{m})\end{array}$ & $\begin{array}{c}\text { Areia } \\
(60 \leq \mathrm{x}<2000 \mu \mathrm{m})\end{array}$ \\
\hline F1 & 41 & 48 & 11 \\
F2 & 37 & 51 & 12 \\
F3 & 36 & 51 & 13 \\
F4 & 35 & 52 & 13 \\
F5 & 33 & 53 & 14 \\
Resíduo & 2 & 72 & 26 \\
\hline
\end{tabular}

Os dados da Tabela II ainda mostram que o resíduo de rocha ornamental estudado contém cerca de 5,04\% de $\mathrm{Fe}_{2} \mathrm{O}_{3}$ e $2,33 \%$ de $\mathrm{CaO}$, que confirmam os resultados de difração de raios X (Fig. 1). A perda ao fogo (PF) é baixa e está dentro da faixa para rochas ornamentais. A massa padrão é constituída basicamente por $\mathrm{SiO}_{2}, \mathrm{Al}_{2} \mathrm{O}_{3}$ e $\mathrm{Fe}_{2} \mathrm{O}_{3}$. O alto conteúdo de ferro é indicativo que a massa padrão apresenta cor avermelhada após queima. A perda ao fogo da ordem de $11,96 \%$ está associada a desidroxilação da caulinita, dehidratação da gibsita e decomposição de matéria orgânica presente na amostra da massa padrão.

Os dados granulométricos são apresentados por faixa de tamanhos de interesse, conforme mostrado na Tabela III. Nota-se que a massa argilosa padrão e o resíduo de rocha ornamental estudados, são também completamente distintos do ponto de vista granulométrico. Assim, o comportamento granulométrico da massa padrão é modificado com a adição do resíduo. Isto se deve a granulometria mais grosseira do resíduo que apresenta elevado teor das frações silte e areia (98\%), que é rica em feldspatos e quartzo. Já a massa padrão

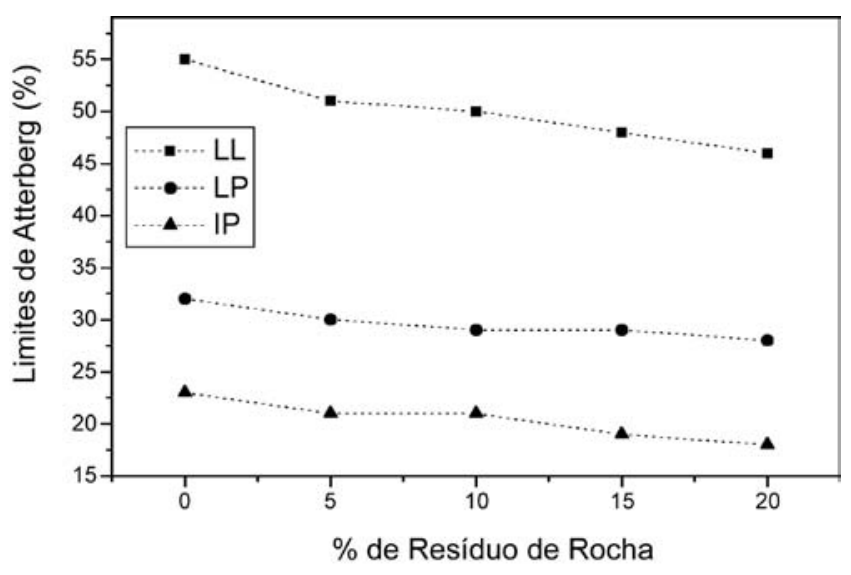

Figura 2: Limites de consistência de Atterberg das massas cerâmicas.

[Figure 2: Atterberg consistency limits of ceramic pastes.] 
Tabela IV - Propriedades dos corpos cerâmicos após secagem.

[Table IV - Properties of ceramic pieces after drying].

\begin{tabular}{ccc}
\hline Amostras & $\begin{array}{c}\text { MEA } \\
\left(\mathrm{g} / \mathrm{cm}^{3}\right)\end{array}$ & $\begin{array}{c}\text { TRF } \\
(\mathrm{MPa})\end{array}$ \\
\hline F1 & $1,76 \pm 0,04$ & $2,21 \pm 0,20$ \\
F2 & $1,76 \pm 0,04$ & $2,23 \pm 0,36$ \\
F3 & $1,77 \pm 0,02$ & $1,30 \pm 0,13$ \\
F4 & $1,79 \pm 0,02$ & $1,34 \pm 0,23$ \\
F5 & $1,79 \pm 0,03$ & $1,47 \pm 0,29$ \\
\hline
\end{tabular}

apresenta elevado teor da fração argila $(<2 \mu \mathrm{m})$, que está relacionada principalmente com a presença do argilomineral caulinita. Apesar da influência da adição do resíduo, todas as massas cerâmicas contendo resíduo apresentam comportamento granulométrico adequado para fabricação de cerâmica vermelha [12].

Os limites de consistência de Atterberg (LL - limite de liquidez, LP - limite de plasticidade e IP - índice de plasticidade, onde IP = LL - LP) em função da quantidade de resíduo adicionada são mostrados na Fig. 2. Verifica-se o efeito desplastificante do resíduo. Quanto maior a quantidade de resíduo adicionada, menor é a plasticidade das massas cerâmicas. De fato os experimentos mostraram que o resíduo de rocha ornamental estudado é um material não plástico.

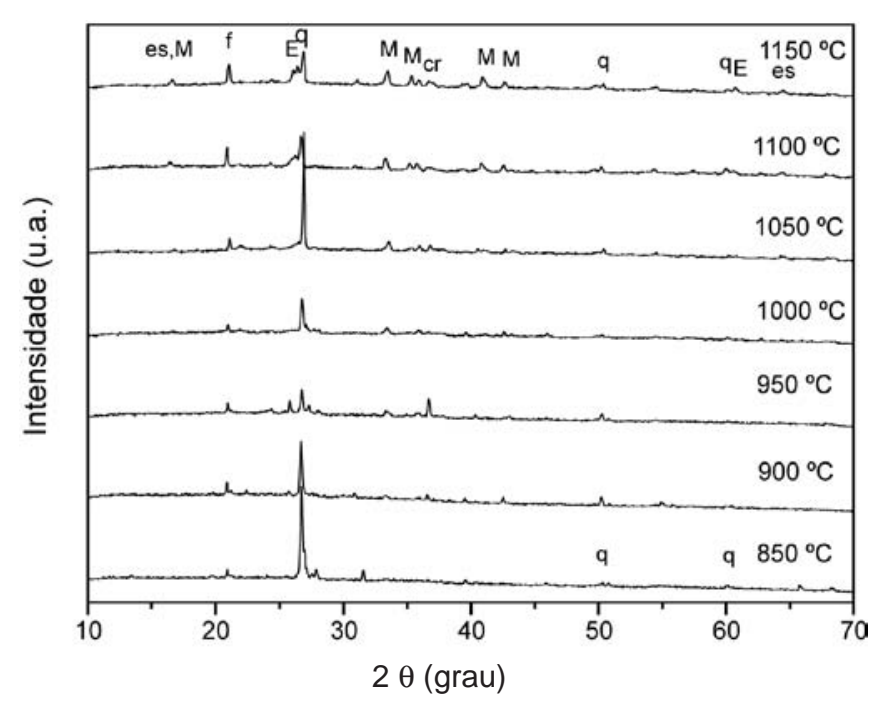

Figura 3: Difratograma de raios X dos corpos cerâmicos sinterizados (amostra F4 - 15\% (em peso de resíduo): M - mulita, q - quartzo, E - $\gamma$-alumina, $\mathrm{f}$ - feldspato potássico, es - espinélio e cr - cristobalita. [Figure 3: $X$-ray diffractograms of sintered ceramic pieces (sample F4- 15 wt.\% waste: $M$ - mullite, q-quartz, $E$ - $\gamma$-alumina, $f$ - potash feldspar, es - spinel, and cristoballite.]

Além do mais, as massas cerâmicas apresentam valores de índice de plasticidade entre 18-23\%, que são adequados para fabricação de cerâmica vermelha [13].

A Tabela IV mostra os valores de massa específica

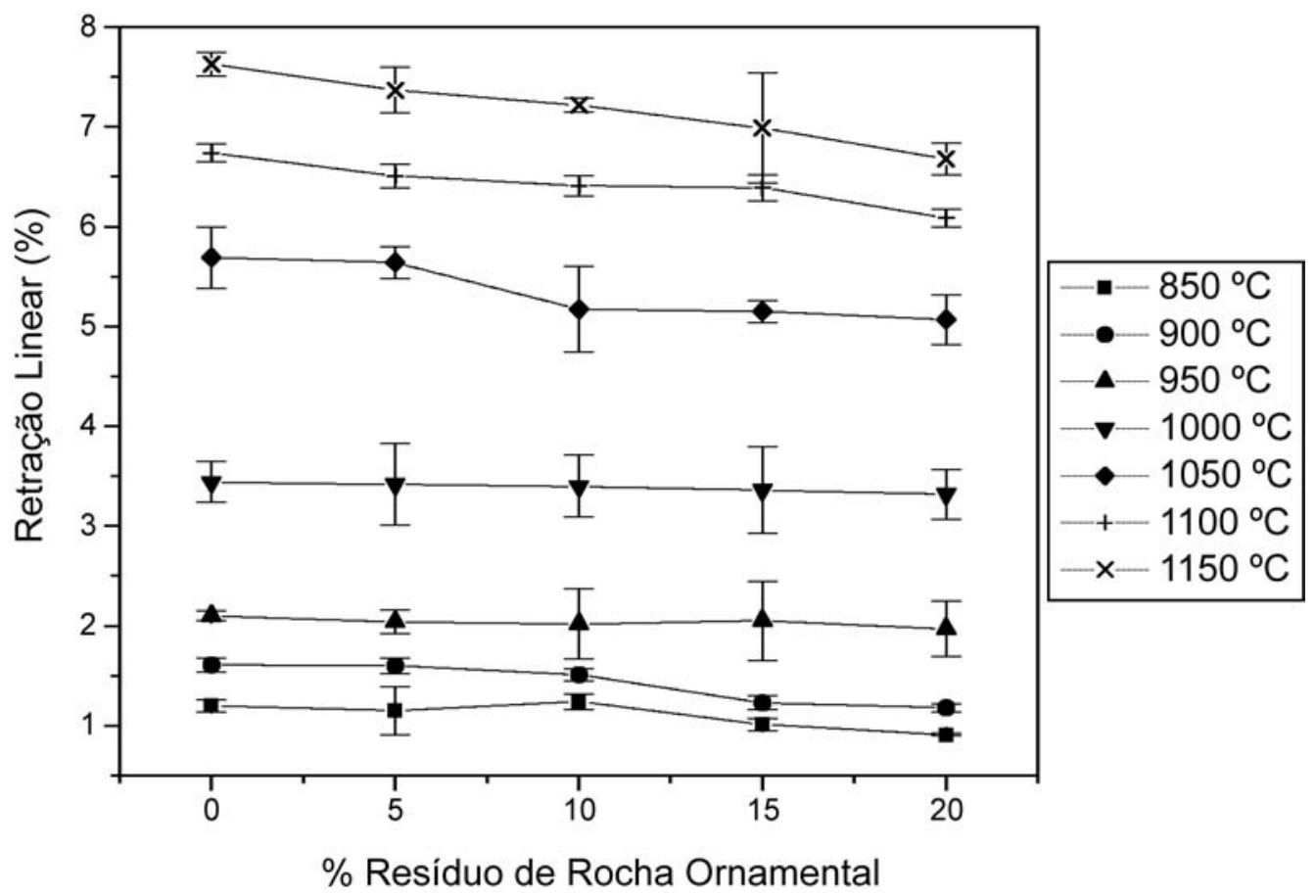

Figura 4: Retração linear dos corpos cerâmicos sinterizados.

[Figure 4: Linear shrinkage of sintered ceramic pieces.] 


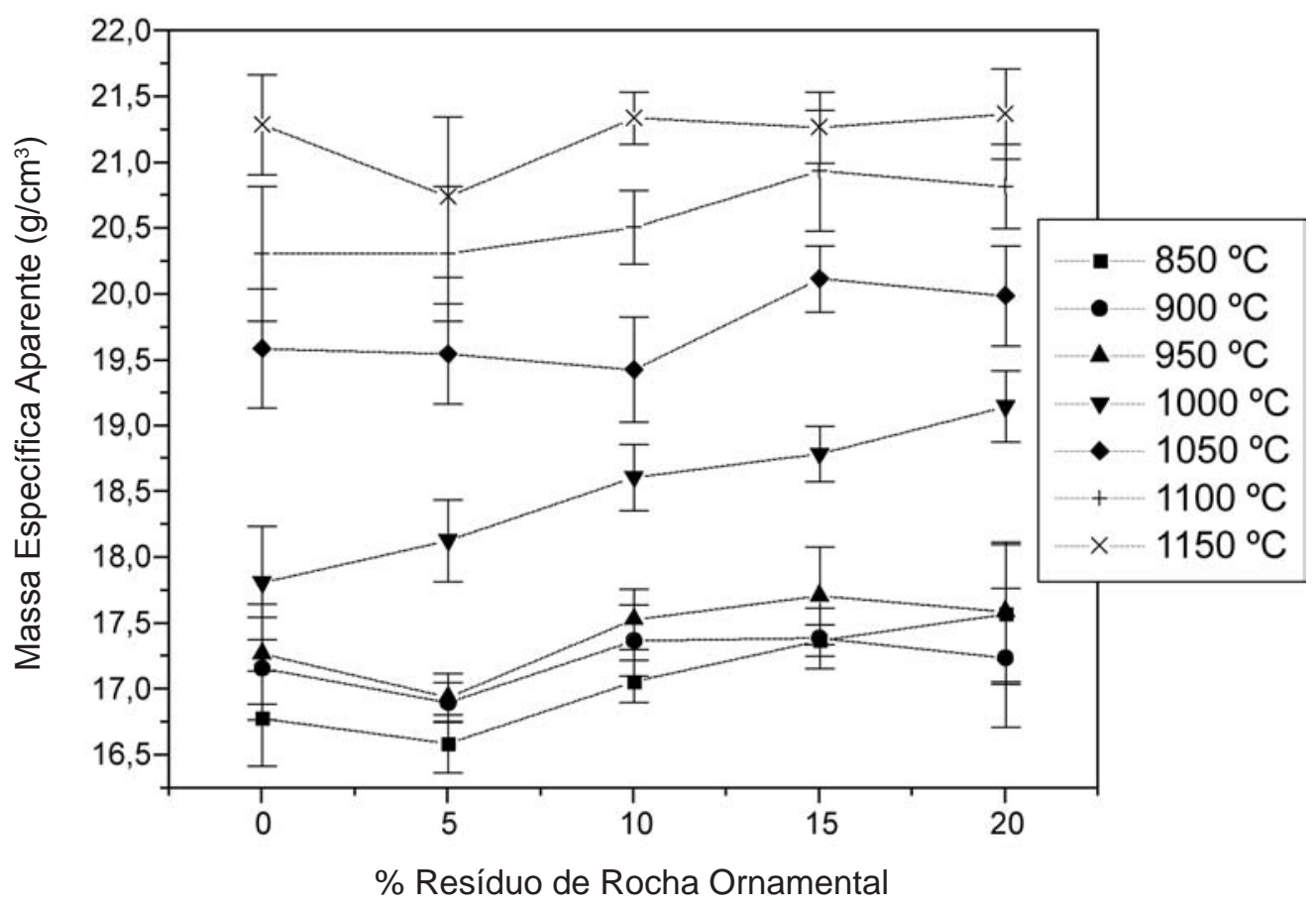

Figura 5: Massa específica aparente dos corpos sinterizados.

[Figure 5: Apparent density of sintered ceramic pieces.]

aparente (MEA) e tensão de ruptura a flexão dos corpos cerâmicos após secagem em $110^{\circ} \mathrm{C}$. Os valores de massa específica aparente apresentam uma leve tendência de aumento com a adição do resíduo. Isto pode estar relacionado ao fato de que as massas contendo maior quantidade de resíduo apresentam maior compactabilidade [14]. A tensão de ruptura apresenta uma tendência de diminuição acima de $5 \%$ de resíduo adicionado.

A Fig. 3 mostra os difratogramas de raios $\mathrm{X}$ para a amostra F4 (15\% em peso de resíduo) queimada entre $850{ }^{\circ} \mathrm{C}$ e $1150{ }^{\circ} \mathrm{C}$. Os resultados mostram que a massa cerâmica contendo resíduo de rocha ornamental apresenta importantes transformações durante o processo de queima, tais como decomposição da caulinita, dehidratação da gibsita, degradação dos feldspatos e o aparecimento de fases como mulita primária, $\gamma$-alumina e espinélio. Estes processos contribuem fortemente para o comportamento de densificação dos corpos cerâmicos.

Os resultados das propriedades físico-mecânicas dos corpos cerâmicos queimados em função da quantidade de resíduo de pó de rocha ornamental são mostrados nas Figs. 4 a 7. Nota-se que a retração linear dos corpos cerâmicos aumenta à medida que se aumenta a temperatura de queima (Fig. 4), como resultado do aumento do grau de sinterização das massas cerâmicas. Acima de $950{ }^{\circ} \mathrm{C}$ verifica-se que a retração linear aumenta significativamente para todas as amostras, independentemente da quantidade de resíduo adicionada. Este comportamento está associado à formação de grande quantidade de fase líquida, bem como à recristalização de fases cerâmicas de alta temperatura. De fato, acima de $950{ }^{\circ} \mathrm{C}$ pode-se observar, a partir dos dados de difração de raios $\mathrm{X}$ (Fig. 3), que são formadas fases tais como mulita primária e $\gamma-\mathrm{Al}_{2} \mathrm{O}_{3}$. Os valores de retração linear obtidos $(0,91$ - 7,63\%) estão dentro da faixa usual para fabricação de cerâmica vermelha. Isso ocorre principalmente devido à abundante presença do quartzo no resíduo, que permite ao corpo cerâmico boa estabilidade dimensional. Os resultados também mostram que o resíduo de rocha ornamental, quando adicionado até $20 \%$ em peso, não provoca modificações significativas nos valores de retração linear.

A Fig. 5 mostra o comportamento da massa específica aparente em função da quantidade de resíduo adicionado e da temperatura de queima. A massa específica aparente aumenta à medida que aumenta a temperatura de queima. Este comportamento acontece em decorrência da sinterização das massas cerâmicas em toda a faixa de temperatura empregada.

Os valores de absorção de água em função da quantidade de resíduo adicionado são mostrados na Fig. 6. Como esperado, a absorção de água diminui com o aumento da temperatura de queima, principalmente acima de $950{ }^{\circ} \mathrm{C}$. Neste caso os fundentes alcalinos do resíduo $\left(\mathrm{K}_{2} \mathrm{O}\right.$ e $\left.\mathrm{Na}_{2} \mathrm{O}\right)$ contribuem para formação de mais fase líquida e, concomitante, para o fechamento da porosidade aberta dos corpos cerâmicos. Ressalta-se, também, que a absorção de água é uma 


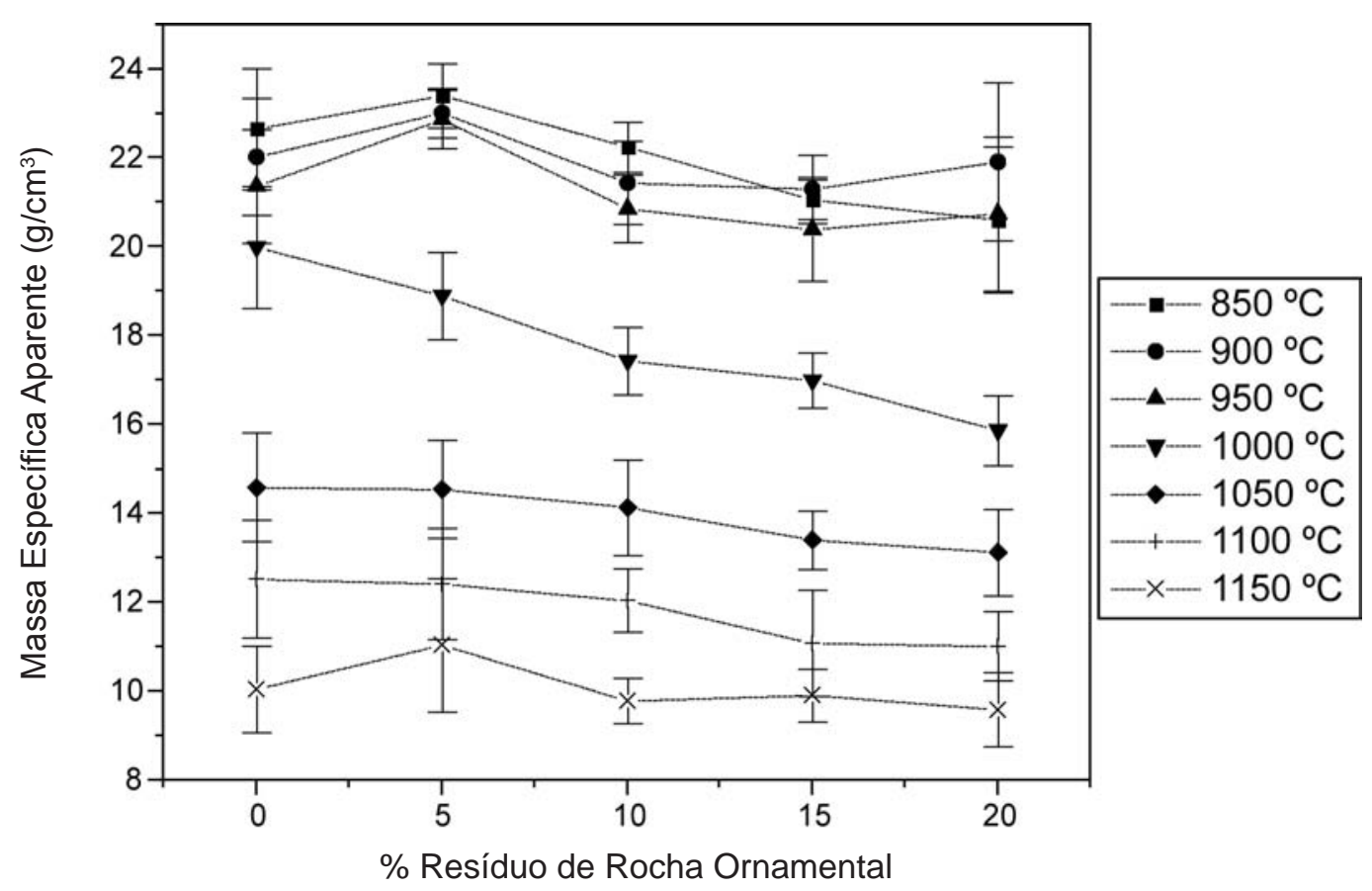

Figura 6: Absorção de água dos corpos cerâmicos sinterizados. [Figure 6: Water absorption of sintered ceramic pieces.]

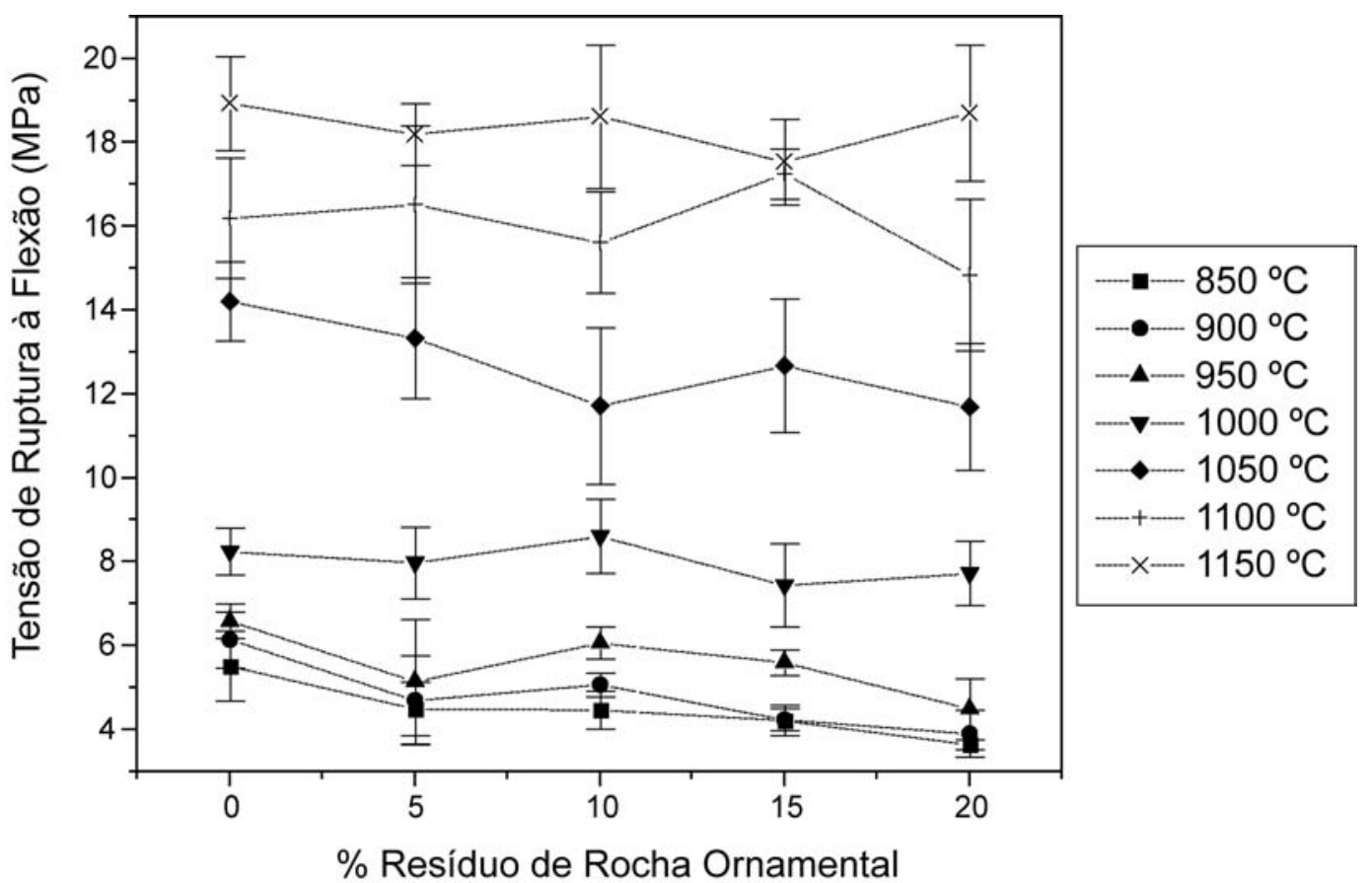

Figura 7: Tensão de ruptura à flexão dos corpos cerâmicos sinterizados.

[Figure 7: Flexural strength of sintered ceramic pieces.]

importante propriedade física dos corpos cerâmicos utilizada para especificar produtos cerâmicos para construção civil. Os resultados mostram que a especificação para tijolos maciços e blocos cerâmicos, em termos de absorção de água $(<25 \%)$, é atingida em toda faixa de temperatura de queima empregada. Enquanto que a especificação para telhas $(<18 \%)$ é atingida somente nas temperaturas mais altas, em geral acima de $950{ }^{\circ} \mathrm{C}$, onde ocorre maior grau de 
sinterização dos corpos cerâmicos.

$\mathrm{O}$ comportamento da tensão de ruptura à flexão dos corpos cerâmicos é mostrado na Fig. 7. Observa-se que a tensão de ruptura é fortemente elevada com o aumento da temperatura de queima, como resultado da diminuição da porosidade nas peças cerâmicas. Verifica-se, também, que a tensão de ruptura não apresentou grandes alterações com a adição do resíduo, similar ao observado para os demais resultados das propriedades estudadas.

\section{CONCLUSÕES}

Os resultados experimentais obtidos indicam que o resíduo de rocha ornamental do tipo gnaisse pode ser utilizado como matéria-prima na formulação de massa argilosa para fabricação de cerâmica vermelha.

O resíduo de rocha ornamental é um material não plástico, cujas fases cristalinas principais presentes são sílica e feldspatos. Além disso, o resíduo é rico em agentes fundentes $\left(\mathrm{K}_{2} \mathrm{O}\right.$ e $\left.\mathrm{Na}_{2} \mathrm{O}\right)$. Os corpos cerâmicos contendo até $20 \%$ em peso de resíduo de rocha ornamental apresentaram propriedades promissoras (retração linear, absorção de água e resistência mecânica) para serem utilizados na fabricação de tijolos maciços, blocos cerâmicos e telhas, dependendo da temperatura de queima.

\section{AGRADECIMENTOS}

Os autores agradecem ao CNPq pelo apoio financeiro.

\section{REFERÊNCIAS}

[1] NITES - Núcleo Regional de Informações Tecnológicas do Espírito Santo, Rochas de qualidade, desperdício na indústria de mármore e granito, Ed. 118 (1994).

[2] http://www.drm.rj.gov.br/potencial.htm (2004).

[3] http://www.cimm.com.br/, Boletim 04 de Janeiro (2004). [4] S. A. Silva, Dissertação de Mestrado, Universidade Federal do Espírito Santo, DEA, Vitória, ES (1998).

[5] R. R. Menezes, H. S. Ferreira, G. A. Neves, H. C. Ferreira, Cerâmica 48, 306 (2002) 92-101.

[6] H. F. M. Filho, H. Polivanov, E. V. Barroso, C. G. Mothé, Thermochim. Acta 392-393 (2002) 47-50.

[7] J. M. S. Moreira, M. N. Freire, J. N. F. Holanda, Cerâmica 49, 312 (2003) 262-267.

[8] P. Torres, H. R. Fernandes, S. Agathopoulos, D. U. Tulyaganov, J. M. F. Ferreira, J. Eur. Ceram. Soc. 24, 10-11 (2004) 3177-3185.

[9] ABNT, NBR 7181-84, Solo: Análise granulométrica (1984).

[10] ABNT, NBR 6459-84, Solo: Determinação de limite de liquidez (1984).

[11] ABNT, NBR 7180-84, Solo: Determinação de limite de plasticidade (1984).

[12] S. Pracidelli, F. G. Melchiades, Cerâmica Industrial 2 (1997) 31-35.

[13] M. Dondi, Technological characterization of clay materials: experimental methods and data interpretation, Int. Ceram. J. (October 2003) 55-59.

[14] M. N. Freire, S. J. G. Souza, A. G. P. Silva, J. N. F. Holanda, Cerâmica 50, 313 (2004) 50-57.

(Rec. 03/11/2004, Rev. 19/04/2005, Ac. 24/06/2005) 